\title{
Um Mercosul de geometria variável: uma nova proposta de integração
}

\author{
Samo Sérgio Gonçalves ${ }^{1}$
}

\section{Resumo}

O objetivo do presente artigo consiste em apresentar uma nova proposta de integração para o Mercosul. A ideia do texto é mostrar que o bloco sul-americano trouxe, e traz inúmeros benefícios ao Brasil. No entanto, dadas às transformações econômicas por que passou o país na última década, o que não ocorreu no caso dos demais países-membros do bloco, verifica-se que o atual modelo de integração não tem mais contemplado os interesses do Brasil. Por isso, uma nova proposta de integração será apresentada no artigo em tela.

Palavras-chave: Mercosul. Assimetrias. Novo modelo de integração

\section{Origem do Mercosul: opção estratégica ou necessidade?}

Existe praticamente um consenso entre especialistas de relações internacionais, políticos, empresários e formadores de opinião no Brasil de que a aproximação com a Argentina e a criação do Mercosul constitui um dos patrimônios da política externa brasileira contemporânea. Realmente, desde então, as rivalidades e os contenciosos entre argentinos e brasileiros reduziram-se, praticamente, aos campos de futebol e às disputas comerciais, afastando, destarte, o risco de conflitos militares. Além disso, nos últimos 25 anos, o processo de integração sub-regional avançou substancialmente, conferindo ao Brasil inúmeros benefícios políticos, econômicos e comerciais.

Nesse sentido, urge analisar, inicialmente, os fatores, domésticos e externos, que contribuíram para o estreitamento de laços entre Brasil e Argentina e, posteriormente, para a formação de um bloco econômico. É lícito afirmar que as transformações ocorridas no âmbito internacional e no plano doméstico em ambos os Estados, em meados

\footnotetext{
${ }^{1}$ Mestre em Relações Internacionais pelo IRI/PUC-RJ e Técnico de Planejamento e Pesquisa da diretoria de relações internacionais (DICOD) do Instituto de Pesquisa Econômica e Aplicada.
} 
da década de 1980, período em que se inicia a aproximação política entre os dois países, foram essenciais para o início da parceria bilateral.

Com efeito, na década de 1980, constatava-se uma miríade de mudanças políticas e econômicas na seara internacional. Em 1985, com a ascensão de Mikhail Gorbatchev ao poder na antiga União Soviética, teve início o fim da era bipolar. O ocaso do período da Guerra Fria permitiu que inúmeros assuntos, até então relegados a um segundo plano e subordinados à lógica do equilíbrio do terror, ganhassem preeminência e fossem inseridos nas discussões da agenda internacional. Assim, com a queda soviética, a temática da segurança perdeu relevância relativa na política internacional, o que contribuiu para reduzir a desconfiança entre nações que apresentavam algum tipo de rivalidade, como era o caso de Brasil e Argentina.

Concomitantemente, no plano político interno, a queda das ditaduras militares tanto na Argentina, em 1983, quanto no Brasil, em 1985, concorreu para desanuviar as tensões entre os dois países. O restabelecimento da democracia permitiu que interesses comuns nos campos da política, da economia e do comércio ganhassem relevância em detrimento de uma perspectiva geopolítica, presente nos governos militares dos dois países. Nesse contexto, Raul Alfonsín e José Sarney deram continuidade ao processo de aproximação política, iniciada com o estabelecimento do Tratado de Itaipu, em 1979, que pusera fim ao contencioso bilateral acerca do aproveitamento das águas da Bacia do Prata (CERVO, 2002).

Assim, em 30 de novembro 1985, os dois presidentes assinaram a Declaração de Iguaçu, por meio da qual ambos os países expressaram pontos-de-vista comuns sobre diversos assuntos internacionais e se criou a Comissão Mista de Alto Nível para a Cooperação e a Integração Econômica Bilateral, cujo objetivo consistia em estudar formas de se promover a integração econômica de Brasil e da Argentina. Os resultados dessa comissão culminaram na assinatura, em julho de 1986, da Ata para Integração e Cooperação Econômica, bem como na ratificação de inúmeros protocolos, representando, assim, o início de uma integração econômica efetiva. ${ }^{2}$

\footnotetext{
${ }^{2}$ Nessa ocasião, Alfonsin e Sarney convidaram o presidente do Uruguai, Júlio Sanguinetti, para participar do encontro, com o intuito de persuadi-lo a participar do projeto de integração futuramente. Vale salientar também,que, no âmbito desse Programa, Brasil e Argentina assinaram, em dezembro de 1986, o Protocolo de Cooperação Nuclear, que previa abertura de seus programas nucleares à inspeção recíproca, com o intuito de por fim às rivalidades e desconfianças no campo nuclear.
} 
Em 1988, os esforços para promover o adensamento das relações bilaterais atingem seu paroxismo com o estabelecimento do Tratado de Integração, Cooperação e Desenvolvimento. Nesse acordo, previa-se uma série de medidas a fim de se estabelecer um mercado comum bilateral em um prazo de 10 anos $^{3}$. A despeito do objetivo ambicioso, tal acordo baseava-se, claramente, em uma perspectiva nacional-desenvolvimentista, uma vez que se previa uma redução gradual das barreiras comerciais, bem como se estabeleciam medidas que visavam à integração das cadeias produtivas de ambas as economias. Esse modelo de associação, que seguia o formato adotado pela Associação Latino-Americana para o Desenvolvimento e Integração (ALADI) de natureza mais protecionista, sofreu, no entanto, alterações no início da década de 1990, em razão do aprofundamento do processo de abertura econômica em curso na América Latina (MENEZES; PIO, 2006).

Com efeito, o processo de liberalização da economia internacional intensificou-se vertiginosamente no início da década de 1980. Desde as eleições de Margareth Thatcher, no Reino Unido, e de Ronald Reagan, nos Estados Unidos, iniciara-se um movimento, impulsionado por ambos os líderes anglo-saxões, de desmantelamento do modelo do Estado do Bem-Estar Social - Welfare State rumo a uma economia mais liberal. Desse modo, a partir de meados da década de 1980, nações latino-americanas que se encontravam em crise econômica - crise da dívida externa - e necessitavam de ajuda financeira passaram a adotar políticas econômicas de cunho liberalizante, ainda que em momentos e em velocidades diferentes (GILPIN, 2002).

Nesse contexto, a Argentina inicia, já em 1985, um processo gradativo de abertura econômica, aprofundando-o a partir do governo Carlos Saul Menen, no início da década de 1990, ano em que o Brasil, governado por Fernando Collor, também começa a implementar, de forma mais acelerada, medidas de liberalização da economia. Seguindo essa nova ideologia econômica, portanto, os dois chefes de Estado assinam, em julho de 1990, a Ata de Buenos, documento que antecipa a data de formação de um mercado comum para dezembro de 1994. Diferentemente do

\footnotetext{
${ }^{3} \mathrm{O}$ Tratado estipulava a remoção gradativa das barreiras tarifárias e não-tarifárias, tanto para o comércio de bens, como para o de serviços, além de projetar a harmonização progressiva das respectivas políticas, macroeconômicas e aduaneiras, rumo à criação de um mercado comum.
} 
Tratado firmado em 1988, o novo acordo regeu-se por uma concepção liberal, visto que estabeleceu um corte linear das tarifas alfandegárias dos dois países em um prazo bastante reduzido e relegou a integração das cadeias produtivas a um segundo plano. ${ }^{4}$

Um ano depois, Paraguai e Uruguai unem-se aos dois sócios maiores para criar o Mercosul. Firmado em março de 1991, o Tratado de Assunção, basicamente, estendia os termos negociados entre Brasil e Argentina aos dois países menores, preservando, portanto, o objetivo de se criar um mercado comum até dezembro de 1994. ${ }^{5}$ Nessa data, ao assinarem o Protocolo de Ouro Preto, os Estados-membros deram um passo importante para aprofundar a integração, na medida em que se instituiu a estrutura institucional do Mercosul, que seria responsável pela formulação e execução de medidas adotadas no bloco comercial. ${ }^{6}$

Dessa maneira, em 1994, concluiu-se uma etapa importante do processo de integração sub-regional, em que foram estabelecidas as bases estruturais do Mercosul. O bloco ainda passaria por mais avanços institucionais. Não obstante, os alicerces da agremiação econômica haviam sido criados, encerrando, portanto, um período importante de consolidação do bloco comercial.

\section{Mercosul: os benefícios de um projeto de Estado}

O bloco sub-regional foi criado com o propósito de se tornar um Mercado Comum, como está estabelecido no artigo primeiro do Tratado de Assunção ${ }^{7}$.

\footnotetext{
${ }^{4}$ Com a Ata de Buenos, estabeleceu-se o que se denomina de "regionalismo aberto". Mais informações, ver: (BAUMAN; CANUTO; GONÇALVES, 2004).

${ }^{5} \mathrm{O}$ Tratado de Assunção é divido em capítulos, artigos e vários anexos. O Acordo estipula, até dezembro de 1994, a livre circulação dos fatores de produção: bens, serviços, mão de obra e capital. Criou-se um cronograma de eliminação progressiva das barreiras alfandegárias, que correspondia à redução semestral de $7 \%$ em todas as tarifas incidentes sobre produtos comercializados entre os quatro países, em um processo que já partiria de uma redução alfandegária inicial linear de 47\% em 30/06/1991.

${ }^{6}$ Com o Protocolo de Ouro Preto, foram criados, além dos já existentes Conselho do Mercado Comum e Grupo do Mercado Comum, a Comissão de Comércio do Mercosul, a Comissão Parlamentar Conjunta, o Foro Consultivo Econômico e Social e a Secretaria Administrativa, com sede em Montevidéu. Mais informações, ver: Vaz (2002).

${ }^{7} \mathrm{O}$ estabelecimento de um Mercado Comum sugere que haja entre os participantes o livre fluxo dos fatores de produção - mão de obra, bens, serviços e capitais - e a coordenação de políticas macroeconômicas. Mais informações, ver: Menezes e Pio (2006).
} 
A despeito dos avanços, passados 18 anos desde a sua formação, o Mercosul ainda não logrou tal objetivo. $\mathrm{Na}$ atualidade, o bloco é caracterizado como União Aduaneira, que compreende não só a existência do livre comércio entre os países-membros, como também o estabelecimento de uma tarifa externa comum. Na verdade, a União Aduaneira do Mercosul ainda enfrenta uma série de problemas que dificulta a harmonização plena do imposto de importação dos integrantes do bloco, por isso a caracterização mais correta seria a de uma União Aduaneira imperfeita. ${ }^{8}$

Ainda assim, quando se observam os últimos 25 anos, período em que se iniciou a reaproximação entre Argentina e Brasil, é inegável que o processo de integração sub-regional trouxe enormes benefícios para a região e, particularmente, para o Brasil. De fato, a despeito dos obstáculos inerentes a um projeto de associação comercial, o Mercosul avançou razoavelmente bem em termos de liberalização comercial, de construção gradativa de um espaço econômico mais integrado no Cone Sul e de criação de um ambiente mais previsível e mais favorável a entendimentos políticos entre os países vizinhos - o Mercosul ajudou no processo de confidence bulding (SANTOS, 2007).

No tocante ao comércio intrabloco, os afluxos comerciais elevaram-se sensivelmente. Em 1991, o Brasil realizava menos de 4\% de seu comércio exterior total na região, ao passo que, em 2007, o comércio intrazona correspondia a $10,8 \%$ das exportações e 9,64\% das importações brasileiras, excluído o comércio com a Venezuela que, em 2007, alcançou US\$ 5,07 bilhões. Em termos de comparação, somente os Estados Unidos, na qualidade de nação individual, têm participação mais elevada nas exportações $(15,6 \%)$ e nas importações $(15,52 \%)$ totais do Brasil ${ }^{9}$ (MERCOSUL, 2008).

Além da expansão dos fluxos de comércio, a formação do bloco concorreu para integrar algumas cadeias produtivas entre os países-membro, mormente,

\footnotetext{
${ }^{8}$ Entre as razões que justificam caracterizar o Mercosul como uma União Aduaneira Imperfeita estão: a dupla cobrança da Tarifa Externa Comum (TEC) e as exceções à TEC que ainda existem para cada país-membro, normalmente denominadas de "perfurações" na TEC.

${ }^{9}$ Em 2007, a participação da China no comércio total do Brasil superou a do Mercosul apenas nas importações (10,4\%). Mais informações, ver sítio do Mercosul (2008). No entanto, os dados comerciais referentes a 2008 parecem indicar que a China superou o bloco comercial, tornando-se o segundo maior parceiro comercial individual do Brasil depois dos EUA. Mais informações, ver ALICE-WEB (2009).
} 
entre Brasil e Argentina. Nessa temática, destaca-se o Acordo Automotivo entre os dois sócios maiores, o que permitiu a segmentação das cadeias produtivas entre as duas nações - que se especializaram na produção de peças e de automóveis distintos -, produzindo, destarte, complementaridades recíprocas entre ambas as economias ${ }^{10}$ (VAZ, 2002).

Ainda em relação ao campo econômico, cumpre salientar que o Mercosul serviu de plataforma para a inserção internacional do Brasil em um contexto econômico complicado. Realmente, fatores como a fragilidade econômica do país no início da década de 1990, decorrente da crise da dívida externa, as pressões liberalizantes sofridas pelos negociadores brasileiros no âmbito da Rodada Uruguai, a estratégia norte-americana de se criar uma área de Livre Comércio na América Latina e a consolidação da "fortaleza" europeia, com a assinatura de Maastricht, contribuíram para que o Brasil utilizasse o Mercado Comum do Sul para proteger sua economia dos desafios econômicos então existentes (ALMEIDA, 2002).

Para Raúl Bernal-Meza (2002), o Mercosul tinha três objetivos para o Brasil: primeiro, o bloco econômico tinha por finalidade ajudar o país a promover uma abertura gradual de sua economia, visto que a ampliação do mercado sub-regional permitiu ao Brasil obter ganhos de escala para enfrentar as economias desenvolvidas; segundo, o Mercosul ajudou o país a enfrentar o desafio da Área de Livre Comércio das Américas, colocado pelos EUA, uma vez que impediu o isolamento brasileiro nas negociações comerciais; e por fim, por meio do Mercosul, o Brasil tinha por objetivo lograr o reconhecimento mundial como potência média, graças à sua preeminência econômica e política no bloco.

Os benefícios proporcionados pela agremiação econômica ao Brasil, todavia, não se restringem ao aspecto comercial. Na realidade, para estudiosos como Maria Regina Soares de Lima (2003), o sucesso do bloco não deve ser aferido somente em termos econômicos, pois o Mercosul é, sobretudo, um projeto político para o Estado brasileiro. Nesse sentido, o bloco teve papel-chave na intensificação

\footnotetext{
${ }^{10}$ Muitos autores também salientam o papel da Tarifa Externa Comum como uma medida de política industrial, responsável pela atração de investimentos para os países da região, principalmente, para o Brasil. Além disso, os países do Mercosul tornaram-se um local propício para as empresas brasileiras iniciarem o seu processo de internacionalização. Mais informações, ver: Almeida (2007).
} 
do diálogo político entre os integrantes, o que ajudou a reduzir os níveis de desconfiança entre os países-membro e a elevar o grau de concertação política desses Estados em relação a assuntos da agenda internacional.

A resistência do bloco às diversas crises econômicas enfrentadas no decorrer dos anos 1990 e 2000, revela a importância conferida ao Mercosul pelas elites políticas dos países-membros. Com efeito, no campo político, constata-se que nem mesmo a tentativa do presidente Carlos Menen de promover "relações carnais" com os Estados Unidos, ao longo da década de 1990, foi capaz de erodir o apoio do país vizinho ao bloco sul-americano, de modo que a Argentina se manteve coesa ao Mercosul durante as negociações da ALCA (GUIMARÃES, 1998). Na seara econômica, os impactos das crises financeiras - asiática (1997), russa (1998), brasileira (1999) e argentina (2001) - tampouco acarretaram o desmantelamento do bloco, ainda que o número de disputas comerciais tenha crescido como consequência das instabilidades financeiras (MENEZES; PIO, 2006).

Nesse sentido, pode-se afirmar que a criação do Mercosul trouxe benefícios iniludíveis aos países que o integram e, em particular, ao Brasil. O estabelecimento do bloco constituiu, portanto, uma estratégia inteligente de inserção no plano externo, por parte do Estado brasileiro, ante o contexto internacional adverso dos anos 1980 e 1990.

Não obstante, tendo em vista as transformações domésticas e externas observadas nos últimos anos, pode-se dizer que, no estágio de integração em que se encontra, o potencial do Mercosul gerar benefícios para o Estado brasileiro parece ter chegado ao fim. Por isso, o bloco sub-regional deveria passar por uma reavaliação de seus objetivos e do modelo de integração adotado, de modo que ele possa continuar a atender os interesses do Brasil e a produzir externalidades positivas para a região.

\section{O Brasil e o Mercosul: a locomotiva e os três vagões vazios}

Por todas as razões anteriormente elencadas, o Mercosul constitui uma das principais realizações da diplomacia brasileira contemporânea. Percebe-se que a consolidação do país como potência regional passa pelo reconhecimento 
da liderança brasileira na América do Sul e, nesse sentido, o sucesso do Mercosul revela-se indispensável para lograr tal objetivo. Ademais, tendo em vista o peso da geografia nas relações externas das nações e o efeito inercial do envolvimento em lentos processos negociadores de natureza econômica, é lícito afirmar que, independentemente do posicionamento ideológico de futuros presidentes do Brasil, o Mercosul e a América do Sul permanecerão como uma das prioridades da política externa brasileira (LIMA, 2004).

Justamente pelo fato de o bloco sub-regional ser um tema-chave e de extrema relevância para as relações internacionais do Brasil, a discussão sobre os rumos do Mercado Comum do Sul revela-se essencial. Nesse sentido, dadas as mudanças ocorridas no sistema mundial e no cenário doméstico brasileiro nos últimos 10 anos, nota-se que tanto as prioridades do Brasil em relação ao Mercosul como o modelo de integração atualmente adotado deveriam ser revistos.

Diferentemente do início da década de 1990, hoje, o Brasil não se encontra fragilizado economicamente e, consequentemente, não necessita posicionar-se defensivamente ante o contexto internacional. Com efeito, no decorrer de quase duas décadas, o país passou por uma série de reformas que fortaleceram a economia brasileira, tornando-a muito mais pujante e preparada para enfrentar eventuais crises internacionais. Atualmente, o Brasil dispõe de bons fundamentos macroeconômicos, sobretudo em relação aos indicadores externos, o que demonstra a maior capacidade de o país suportar instabilidades financeiras internacionais. ${ }^{11}$

Além disso, após a abertura da economia, a indústria brasileira teve de se adaptar à concorrência internacional, o que a forçou a passar por um processo de reestruturação e modernização. Dessa forma, diferentemente do que ocorreu na

${ }_{11}$ O Brasil, nos últimos 15 anos, foi capaz de resolver o problema da inflação e forjar um arcabouço macroeconômico mais próximo de países "normais". O modelo que conjuga superávit primário, câmbio flutuante e metas de inflação, tem permitido ao país concentrar esforços na retomada do crescimento econômico. Atualmente, o Brasil apresenta bons fundamentos macroeconômicos, tais como: uma inflação baixa, em torno de $6 \%$ ao ano; superávit primário que varia entre $3 \%$ a $4,5 \%$ ao ano; relação dívida/PIB próxima de $40 \%$ ao ano; superávits em transações correntes nos últimos cinco anos e reservas internacionais superiores US\$ 200 bilhões de dólares. A maior demonstração de força da economia brasileira tem sido o impacto da atual crise financeira mundial, a maior desde a de 1929, sobre o Brasil. Enquanto as projeções para a maior parte dos países do mundo são de forte recessão em 2009, para a economia brasileira, a perspectiva é um crescimento entre $1 \%$ e $2 \%$. 
Argentina, em que a maior parte das empresas sucumbiu à competição externa ao longo dos dez anos de vigência do regime de currency board, ${ }^{12}$ no Brasil, o parque industrial brasileiro resistiu à abertura da economia na década de 1990. Como reflexo dessas mudanças, inicia-se, a partir da década de 2000, um processo de internacionalização de empresas brasileiras, que passam a prospectar oportunidades de negócios e mercados fora do país. Surgem no Brasil, portanto, algumas multinacionais que se tornam líderes globais em alguns segmentos importantes do mercado mundial (ALMEIDA, 2007).

Concomitantemente e, até certo ponto, como decorrência dessas mudanças internas, também ocorreram transformações no sistema internacional. Grandes economias emergentes, como os chamados BRICs, ${ }^{13}$ vêm ampliando sua participação na riqueza e nos fluxos de comércios mundiais, em detrimento de economias de países desenvolvidos. Ao contrário do final da década de 1990, em que países como Rússia e Brasil tiveram de recorrer ao Fundo Monetário Internacional (FMI) para enfrentar a crise financeira mundial, hoje, os grandes países emergentes tornaram-se poupadores e exportadores de capital. Estados como a China e o Brasil estão entre os grandes financiadores do déficit externo dos Estados Unidos. ${ }^{14}$

Essas mudanças na economia mundial têm, por sua vez, reflexos nas relações de poder no sistema internacional. Realmente, países emergentes de maneira geral e, em especial, o Brasil, tornaram-se indispensáveis em foros como as Nações Unidas, o Fundo Monetário Internacional e a Organização Mundial do Comércio, em que o Brasil saiu de uma posição marginal e reativa nas negociações da Rodada Uruguai, em que tentava atenuar o impacto das decisões tomadas pelas economias desenvolvidas, para ocupar um lugar central e pró-ativo nas discussões da Rodada

\footnotetext{
${ }^{12}$ Em 1991, foi implantado na Argentina o chamado Plano Cavallo, que fixou, na Constituição do país, a paridade de 1:1 entre o peso argentino e o dólar norte-americano. Esse sistema, chamado de currency board, acirrou a competição no mercado argentino, uma vez que os bens importados tornaram-se mais baratos. Isso acarretou um processo de desindustrialização do país. Esse sistema só foi extinto em 2002, após a grave crise econômica enfrentada pelo país em 2001. Mais informações, ver: Krugman (2009).

${ }^{13}$ Sigla criada em 2001, por dois economistas do Goldman Sachs, com as iniciais dos países Brasil, Rússia, Índia e China. Nessa ocasião, ambos revelaram um estudo que apontava que essas quatro economias se tornariam a maiores e mais importantes do mundo por volta da década de 2030. Mais informações, ver :O’Neill (2001).

${ }^{14}$ A China e o Brasil são, respectivamente, o primeiro e o quarto maiores financiadores do déficit em conta corrente dos EUA. Mais informações, ver FEDERAL RESERVE (2009).
} 
Doha. Nesta, a diplomacia brasileira liderou a criação do G-20, ${ }^{15}$ o que equilibrou as negociações multilaterais, impedindo, assim, que prevalecessem tão-somente os interesses das nações desenvolvidas na formulação das regras comerciais internacionais.

Percebe-se, portanto, que o Brasil se encontra, claramente, em um patamar mais elevado no âmbito da política e da economia mundiais. A ascensão relativa do país na hierarquia do poder mundial nos últimos anos distanciou-o, ainda mais, de seus parceiros do Mercosul, cujas economias não passaram por um processo de modernização semelhante ao experimentado pelo Brasil.

De fato, após anos de crescimento econômico, a Argentina, somente em 2008, recuperou os níveis de riqueza existentes antes da crise econômica de 2001. ${ }^{16}$ Além disso, a moratória declarada pelos argentinos em 2002, que alijou o país dos mercados financeiros internacionais, aliada a uma gestão macroeconômica $\mathrm{du}$ vidosa, pode comprometer o potencial de crescimento do país a médio e longo prazo. ${ }^{17}$ Nos casos do Paraguai e do Uruguai, ainda que essas pequenas economias tivessem se fortalecido industrialmente, o que não ocorreu, as assimetrias econômicas em relação ao Brasil permaneceriam monumentais, tendo em vista os diferenciais em termos de recurso de poder. ${ }^{18}$

Nesse contexto, um rearranjo do Mercosul faz-se necessário para que o bloco que, durante anos beneficiou o Brasil ao ser utilizado como instrumento de

${ }^{15}$ Grupo criado na Conferência Ministerial de Cancun, em 2003, composto por cerca de 20 grandes economias emergentes que negociavam com uma só voz em relação às questões agrícolas.

${ }^{16}$ Segundo dados do Fundo Monetário Internacional, em 2001, o PIB argentino, medido em dólares (preços correntes) em 2001 foi de US\$268.697.000 bilhões de dólares. Em 2007, o PIB do país foi de US\$260.122.000 bilhões, portanto, menor do observado em 2001. Apenas em 2008, o PIB argentino superou o valor referente a 2001. Em termos de PIB per capita, também se constata que o valor de 2001, US\$ 7.231 mil dólares é superior ao de 2007, que é de 6.609 mil dólares. Mais informações, ver: FMI (2009).

${ }^{17} \mathrm{O}$ governo argentino de Cristina Kirchner vem sendo acusado, desde 2008, por especialistas e por diversos meios de comunicação, de manipulação dos índices de inflação do país. Segundo analistas, o instituto responsável por medir os índices de inflação do país, o INDEC, tem deliberadamente divulgado índices de inflação menores do que os efetivamente registrados em função do controle político exercido sobre o instituto.

${ }^{18}$ A soma dos PIBs do Uruguai e do Paraguai corresponde a menos de 6\% do PIB brasileiro. Mais informações, ver o estudo feito pela Secretaria do MERCOSUL Asimetrías em El Mercosur: son compatibles com el proceso de integración? 
inserção internacional em um contexto externo desfavorável, continue a atender aos interesses brasileiros nessa nova realidade internacional, em que o país desponta como uma potência média em ascensão. Aliás, segundo as palavras de Maria Regina Soares de Lima (2004, p. 17), esse parece ser o desejo da comunidade de política externa brasileira: “É curioso que, apesar de todas as mudanças domésticas e internacionais, tenha se mantido o consenso dentro da comunidade de política externa com respeito à valorização de um papel protagônico para o país”.

Nesse sentido, uma eventual adequação do Mercosul a essa nova realidade deveria basear-se em um modelo de integração de geometria variável, em que a velocidade e o grau de aprofundamento das relações do bloco variassem de acordo com os interesses do Brasil em relação à área discutida. Dessa forma, os níveis de integração no âmbito político, econômico, social e de infraestrutura seriam estabelecidos em patamares diferentes que se alterariam consoante os interesses brasileiros. Na busca desses interesses, a diplomacia brasileira ora poderia se revestir de uma visão realista clássica, ora poderia se pautar por uma perspectiva neoliberal institucionalista. ${ }^{19}$

\section{Um Mercosul de geometria variável: uma nova proposta de integração}

Com base na proposta de remodelação do Mercosul supracitada, serão esboçadas, ainda que de forma embrionária e sucinta, algumas ideias e proposições de mudanças na forma como o Brasil deveria conduzir o processo de integração sub-regional. Como anteriormente mencionado, tendo em vista as acentuadas disparidades de poder entre os países-membro e o tipo de integração que melhor atenderia aos interesses do Brasil no âmbito do Mercosul, a diplomacia brasileira deveria promover um modelo de "minimalismo institucional", em

\footnotetext{
${ }^{19} \mathrm{O}$ termo realista é utilizado aqui no sentido da teoria realista clássica, que percebe, em função da anarquia internacional, as relações internacionais com base no princípio do autointeresse (self-help) e na procura por ganhos relativos. Já a perspectiva do neoliberalismo institucional refere-se ao uso de instituições, como o Mercosul, como uma maneira de promover maior cooperação, uma vez que a criação desses organismos contribui para gerar maior transparência e previsibilidade, reduzindo, assim as desconfianças entre os países-membros. Para mais informações, ver: Messari e Nogueira (2005).
} 
que predominasse uma estrutura intergovernamental leve e enxuta, já que a menor institucionalização do Mercosul tende a beneficiar o Brasil, pois garante a manutenção do seu diferencial de poder e lhe assegura maior autonomia de atuação. No tocante à integração política, portanto, a abordagem realista parecer ser a que melhor se coaduna aos interesses brasileiros.

Para implementar tal arcabouço institucional no Mercosul, seria preciso rever o processo decisório atualmente vigente no âmbito das instituições do blo$\operatorname{co}^{20}$ Baseado na regra do consenso, o atual sistema não leva em consideração a diferença no peso relativo dos países membros. Como mencionado anteriormente, o Brasil é, atualmente, responsável por cerca de $79 \%$ da população e por volta de $81 \%$ do PIB do Mercosul (FMI, 2009). Tendo em vista tamanhas assimetrias, faz-se necessário que os países-membros reconheçam o diferencial de poder brasileiro e adotem um sistema que se baseie no voto ponderado, de modo que a representação política do Brasil seja consentânea ao seu peso político e econômico. ${ }^{21}$

Diferentemente dessa proposição, muitos estudiosos brasileiros das relações internacionais defendem o aprofundamento da integração política e, em especial, a adoção de instituições supranacionais, ${ }^{22}$ como forma de solucionar os problemas que eventualmente surgem no Mercosul. Com efeito, logo após a maxidesvalorização da moeda brasileira, em 1999, que deu ensejo a uma profunda crise econômica

${ }^{20}$ Nos três principais órgãos com poder decisório do Mercosul - o Conselho de Mercado Comum, o Grupo de Mercado Comum e a Comissão de Comércio do Mercosul -, as decisões são tomadas por consenso.

${ }^{21}$ Cumpre salientar, todavia, que o sistema de voto ponderado que vier a ser adotado, deverá, necessariamente, buscar um equilíbrio entre o peso relativo do Brasil e a legitimidade do bloco. Assim, para que os demais parceiros adiram ao Mercosul e o vejam como legítimo, o Brasil não deve ter um peso estritamente proporcional, ainda que justificável, aos seus recursos de poder. A representação política brasileira deve, sim, ser maior que a dos demais membros, mas deverá ser relativamente menor do que aquela a que o país teria direito a ter. O Brasil terá de fazer uma concessão semelhante à que as maiores economias europeias fizeram nos tratados de Roma e de Nice, em que o peso relativo desses países no processo decisório, embora maior que o dos países menores, foi reduzido para incentivar a adesão de economias menores e para conferir maior legitimidade ao processo de integração. Mais informações, ver: Magnoli (2004).

${ }^{22} \mathrm{O}$ conceito de supranacionalidade está assentado sobre dois princípios: a) o da eficácia direta das decisões tomadas, ou seja, as normas emanadas dos órgãos supranacionais não necessitam passar pelo crivo parlamentar dos países-membros para entrar em vigor; b) as normas criadas pelas instituições supranacionais sobrepõem às normas internas dos estados-membros do bloco. Mais informações, ver em: Junior e Ratton (2002). 
e política no bloco, muitos especialistas passaram a apontar a supranacionalidade como a melhor opção para solucionar a crise do Mercosul. Afirmava-se que a existência de tais instituições impediria a eclosão de novos contenciosos comerciais e políticos.

Seguindo essa linha de pensamento, uma das principais especialistas em política externa brasileira, Maria Regina Soares de Lima (2004), propugna a tese de que é preciso manter a coalizão doméstica brasileira a favor do aprofundamento da integração política do Mercosul e da construção de instituições supranacionais. Segundo a politóloga, a erosão desse patrimônio - coalizão doméstica - teria como consequências "uma integração rasa, o aparente abandono de uma estratégia de aprofundamento da integração" (LIMA, 2006, p. 5).

A defesa da adoção de instituições supranacionais por Lima e por outros acadêmicos brasileiros fundamenta-se no relativo sucesso de integração obtido pelo bloco europeu, a União Europeia, que foi aprofundando seu processo por meio do estabelecimento de organismos supranacionais. Ancorando seus argumentos em premissas teóricas baseadas na perspectiva Funcionalista, ${ }^{23}$ esses estudiosos alegam que, por meio da cooperação funcional no âmbito dessas instituições de caráter supranacional, as nações europeias conseguiram pôr fim a conflitos armados que subsistiam há séculos no continente. Asseveram, ademais, que tais organizações também concorreram para impulsionar o processo de integração econômica, culminando na instituição de uma União Econômica e Monetária (A. JÚNIOR; RATTON, 2002).

A União Europeia deve, sim, ser observada atentamente pelas autoridades brasileiras, uma vez que é um processo que se iniciou há mais tempo, o estágio de integração encontra-se em nível mais profundo e o bloco dispõe de inúmeras políticas que poderiam ser adaptadas no âmbito do Mercosul. ${ }^{24}$

Em que pese a experiência europeia, o estabelecimento de instituições supranacionais no bloco sul-americano não será capaz de evitar o surgimento de disputas políticas e econômicas entre os países-membros, já que esses órgãos

\footnotetext{
${ }^{23}$ Para obter mais informações sobre a Teoria Funcionalista, ver: Herz e Hoffman (2004).

${ }^{24}$ Como, por exemplo, os Fundos Estruturais, o Fundo de Coesão e o Banco Europeu de Investimentos, entre outros, que visam a reduzir as assimetrias entre os países-membros da União Europeia.
} 
não resolvem, por si sós, as assimetrias estruturais e os problemas conjunturais do Mercosul. Ao contrário da União Europeia, na qual as disparidades não são tão acentuadas, as diferenças econômicas, territoriais e demográficas no Mercosul não apenas são profundas, mas também se agravaram nos últimos anos.

Em 1991, a população e o PIB brasileiros, que correspondiam a cerca de $78 \%$ e $68 \%$ do bloco, respectivamente, ampliaram-se para $79 \%$ e $81 \%$ em 2007. Da produção de manufaturas na sub-região, $78 \%$ é de origem brasileira, 20\% argentina, 1,3\% uruguaia e 0,4\% paraguaia (FMI, 2008). Além dessas assimetrias estruturais, existem também diferenças conjunturais no Mercosul, que decorrem não só do descompasso de ritmos e profundidades dos ciclos econômicos de cada país, mas também da adoção de políticas econômicas distintas em sua natureza e substância. Essas diferenças, por sua vez, só tendem a se agravar na ausência de políticas macroeconômicas harmonizadas ${ }^{25}$ (BARBOSA, 2009).

Nesse sentido, enquanto perdurarem essas enormes disparidades entre os parceiros contenciosos, sejam comerciais, sejam políticas, provavelmente ocorrerão no Mercosul, sobretudo em períodos de crise econômica. Instituições supranacionais não podem impedir o surgimento de tais conflitos. Tampouco se pode afirmar que elas disponham de eficácia superior aos atuais órgãos intergovernamentais do Mercosul na resolução dessas disputas ou na promoção da cooperação. Como sublinha Paulo Roberto de Almeida (2002, p. 97-110):

[...] a construção de órgãos supranacionais que não serão capazes [...] de resolver os problemas conjunturais e as assimetrias estruturais do Mercosul [...] não sou absolutamente partidário, neste momento, da adição de um regime de direito comunitário, ou supranacional, para o Mercosul. Penso que tal opção corresponde mais ao terreno das utopias acadêmicas do que ao campo das possibilidades concretas.

\footnotetext{
${ }^{25}$ Um exemplo seriam os distintos regimes cambiais aplicados por Brasil e Argentina na década de 1990. Enquanto esta adotou a ancoragem cambial (currency board), aquele pôs em vigor um regime de flutuação controlada. Além disso, desde o final dos anos 1990, o Brasil passou a adotar o regime de metas de inflação, que permanece até hoje, ao passo que o governo argentino de Cristina Kirchner tem, deliberadamente, manipulado os índices de inflação do país. Emblemática também foi a maxidesvalorização do real, consequência da crise financeira de 1999, que gerou reações protecionistas na vizinha Argentina.
} 
Assim, é importante frisar que a resposta aos problemas políticos ou econômicos que, eventualmente, surgirão em um bloco em formação como Mercosul não está no mero aprofundamento da integração, nem na constituição de órgãos supranacionais. Com efeito, para construir um bloco econômico no qual seja possível haver relações mais harmoniosas entre os países-membros e os interesses brasileiros sejam contemplados, não basta haver mais integração, mas, sim, uma integração melhor.

$\mathrm{Na}$ realidade, um modelo de integração regional, cuja estrutura políticoinstitucional seja branda com o propósito de manter a autonomia e a flexibilidade do Brasil, não significa que a integração do Mercosul deverá ser, necessariamente, superficial. O diálogo político pode e deve ser intenso no âmbito dessas estruturas intergovernamentais. Os encontros entre os representantes dos países-membros, seja em nível presidencial, seja em nível ministerial, seja em nível técnico, podem ocorrer regularmente, de modo a se aprofundar a cooperação sub-regional e a se buscarem soluções tanto para os desafios do bloco quanto para contenciosos que, eventualmente, surjam entre os parceiros.

Com efeito, nada impede que projetos comuns, que visem a aprofundar a integração, sejam formulados no seio de um arcabouço institucional minimalista. Uma institucionalização branda não impediria que os países-membros do Mercosul elaborassem políticas com o intuito de promover o aprofundamento das cadeias produtivas dos integrantes do bloco, criassem medidas que impulsionassem a integração da infraestrutura - viária, energética e de telecomunicações - entre os países-membros, estabelecessem convênios que ampliassem o crédito às pequenas e médias empresas do bloco e produzissem incentivos que favorecessem a internacionalização das empresas do Mercosul. Nota-se, portanto, que a existência de uma estrutura intergovernamental leve e enxuta não impediria o aprofundamento da integração da agremiação sub-regional.

A defesa de um arcabouço institucional minimalista no âmbito do bloco sul-americano, que permita ao Brasil valer-se de seus diferenciais em termos de recursos de poder, quando necessários, não significa, ademais, que o país deva eximir-se de liderar e dar prosseguimento ao processo de integração. De fato, cumpre ao Brasil, na qualidade de país mais rico, arcar com a maior parte dos custos de implementação de medidas que contribuam para uma maior integração 
entre os parceiros do Mercosul. Consoante Lima (2006, p. 3), uma política externa solidária, em relação aos seus parceiros do bloco, não significa que os interesses nacionais não estejam sendo contemplados. Pelo contrário, “abrir mão de ganhos no curto prazo para obter benefícios no médio e longo prazo" faz parte do "autointeresse esclarecido" do Brasil.

Assim, ao arcar com a maior parte dos custos referentes aos projetos de integração econômico e social, o Brasil legitima sua liderança no âmbito do Mercosul, o que lhe rende benefícios, seja por meio de apoio político dos demais membros em foros internacionais, seja mediante o incremento das exportações e dos investimentos brasileiros para os parceiros do bloco. ${ }^{26}$ Diferentemente da integração política, portanto, a integração socioeconômica do Mercosul deveria pautarse por uma perspectiva neoliberal institucionalista, que tem por fim uma maior cooperação institucional.

Nesse sentido, a diplomacia brasileira deveria envidar esforços para impulsionar a cooperação em projetos de integração econômica, social e de infraestrutura com vistas a reduzir as assimetrias, diminuir os custos de transação e maximizar os ganhos - absolutos no âmbito do Mercosul. De fato, embora seja do interesse brasileiro uma estrutura político-institucional que preserve seu diferencial de poder no processo decisório, um Mercosul economicamente pujante e socialmente mais equilibrado revela-se igualmente importante para os interesses brasileiros.

À vista do exposto, é possível asseverar que uma reavaliação do atual modelo de integração adotado pelo Mercosul é essencial. Como anteriormente mencionado, à luz da crescente ascensão brasileira na hierarquia do sistema internacional, o bloco sub-regional deveria ajustar-se a essa nova realidade, de forma que o Brasil pudesse extrair maiores benefícios dessa associação político-comercial. Seguindo esse objetivo, a diplomacia brasileira poderia considerar um arranjo de integração de geometria variável, em que a velocidade e o grau de integração variassem de acordo com os interesses do Brasil.

${ }^{26}$ Nesse sentido, a recente criação do Fundo Convergência Estrutural do Mercosul (FOCEM/2006), inspirado no modelo existente na União Europeia, que visa a destinar empréstimos a fundo perdido para financiar projetos de desenvolvimento socioeconômico nos países e nas regiões mais pobres do bloco, revela-se muito apropriada, visto que constitui uma ferramenta fundamental para diminuir as assimetrias econômicas e sociais do Mercosul. Para saber mais sobre o FOCEM e sobre os Projetos em curso, ver em: FOCEM (2009). 
No tocante à integração política do bloco, constatou-se que a política externa brasileira deveria reger-se por princípios realistas, com base nos ganhos relativos, ao passo que, em relação à integração socioeconômica, o Brasil deveria pautar-se por premissas neoliberal-institucionalistas, enfatizando a cooperação e os ganhos absolutos. Dessa maneira, o Brasil poderia, por meio das instâncias políticas decisórias, recorrer ao seu diferencial de poder para influenciar nos rumos da integração, seja decidindo a favor de projetos socioeconômicos que beneficiassem aos demais parceiros e, concomitantemente, se ajustassem aos interesses político-econômicos brasileiros, ou seja vetando propostas que, de alguma forma, não se coadunassem aos propósitos do país.

\section{A new proposal of integration: a Mercosur of variable geometry}

\section{Abstract}

The objective of this article is to present Mercosur a new model of integration. The purpose is to show that the South American block has brought a myriad of benefits to Brazil. However, given the economic transformations that the Brazilian economy went through in the past decade, which did not occurred in the others countries of Mercosur, it is apposite to sustain that the current integration model no longer fits Brazilian interests. That is why a new model of integration will be presented in this article.

Keywords: Mercosur. Asymetries. New model of integration.

\section{Referências}

A. JUNIOR, A.; RATTON, M (Org.). União Europeia. São Paulo: Aduaneiras, 2002.

ALICE-WEB. Sítio. Brasília, 2009. Disponível em: <http://aliceweb. desenvolvimento.gov.br/>. Acesso em 16 jul. 2009.

ALMEIDA, A. (Org.). Internacionalização de empresas brasileiras: perspectivas e riscos. Rio de Janeiro: Elsevier, 2007. 
ALMEIDA, P. R. Mercosul e ALCA na perspectiva do Brasil: uma avaliação política sobre possíveis estratégias de atuação. Brasília: Câmara dos Deputados, 2002. Disponível em: <http://www.pralmeida.org/05DocsPRA/ 798MSulAlca.html>. Acesso em: 17 jul. 2009.

ALMEIDA, P. R. MERCOSUL em sua primeira década (1991-2001): uma avaliação política a partir do Brasil. Buenos Aires: Intal, 2002. Disponível em: <http://www. iadb.org/intal/detalle_publicacion.asp?idioma_pub $=\& C i d=234 \&$ pid $=73 \&$ tid $=8 \&$ ?cid=234\&idioma=POR\&tipo=>. Acesso em: 16 jul. 2009.

BARBOSA, R. Brasil e Argentina: contrastes e confrontos no âmbito do MERCOSUL. Política Externa, São Paulo, v. 18, n. 1, jun./ago. 2009.

BAUMAN, R; CANUTO, O; GONÇALVES, R. Economia internacional: teoria e experiência brasileira. São Paulo: Campus, 2004.

BERNAL-MEZA, R. A Política Exterior do Brasil: 1990 a 2002. RBPI, Brasília, ano 45, n. 1, p. 36, 2002.

CERVO, A. L.; Bueno, C. História da política exterior do Brasil. Brasília: UnB, 2002.

COUTINHO, Luciano; FURTADO, João. A integração continental assimétrica e acelerada: riscos e oportunidades da ALCA. In: . ALCA e Mercosul: riscos e oportunidades para o Brasil. Rio de Janeiro: IPRI, 1998.

FEDERAL RESERVE. [Home page]. Washington D.C., 2009. Disponível em: $<$ http://www.federalreserve.gov/>. Acesso em: 16 jul. 2009.

FMI. Sítio. Washington, D.C., 2009. Disponível em: <http://www.imf.org/external/ index.htm>. Acesso em: 15 jul. 2009.

FOCEM. Sítio. Montevidéu, 2009. Disponível em: <http://www.mercosur.int/ focem/index.php?c=2118\&i=2\&id=>. Acesso em: 16 jul. 2009.

GILPIN, R. Economia política das relações internacionais. Brasília: UnB, 2002.

GUIMARÃES, S. P. A ALCA e o fim do Mercosul. In: ALCA e Mercosul: riscos e oportunidades para o Brasil. Rio de Janeiro, IPRI, 1998.

HERZ, M; HOFFMAN, A. R. Organizações internacionais: história e práticas. São Paulo: Campus, 2004. 
KRUGMAN, P. A crise de 2008: a economia da depressão. São Paulo: Campus, 2009.

LIMA, M. R. S. Aspiração internacional e política externa. [S.1.], 2004. Disponível em: <http://www.scribd.com/doc/7259592/Mrs-Lima-Aspiracao-Internacional-ePolitica-Externa>. Acesso em: 07 ago. 2009.

LIMA, M. R. S. Decisões e indecisões: um balanço da política externa no primeiro governo do presidente Lula. [S.1.], 2006. Disponível em: <http://observatorio. iuperj.br/pdfs/78_artigos_Decisoes-e-indecisoes.pdf.>. Acesso em: 25 jul. 2009.

LIMA, M. R. S. Na trilha de uma política externa afirmativa. [S.1.], 2003. Disponível em: <http://www.socialwatch.org/en/informeImpreso/pdfs/ panorbrasileirog2003_bra.pdf>. Acesso em 05 ago. 2009.

MAGNOLI, D. União Europeia: história e geopolítica. São Paulo: Moderna, 2004.

MENEZES, M. A; PIO, P. F. Integração regional: os blocos econômicos nas relações internacionais. São Paulo: Campus, 2006.

MERCOSUL. Página brasileira do Mercosul. Brasília, 2008. Disponível em: <http:// www.mercosul.gov.br/>. Acesso em: 02 ago. 2009.

MESSARI; NOGUEIRA, J. P. Teoria das relações internacionais: correntes e debates. São Paulo: Campus, 2005

O’NEILL, J. Building better global economic brics. Global Economics Paper, [S.1.], n. 66, 30 nov. 2001. Disponível em: <http://www2.goldmansachs.com/ideas/brics/ brics-dream.html.>. Acesso em: 12 jul. 2009.

SANTOS, M. C. M. Mercosul entre discurso e prática: desafios para a implementação de um projeto político. 2007. 112 f. Dissertação (Mestrado em Ciência Política)Universidade Federal do Rio de Janeiro, Rio de Janeiro, 2007.

VAZ, Alcides Costa. Cooperação, integração e processo negociador: a construção do Mercosul. Brasília: IBRI, 2002. 
